Research Article

\title{
Implicit Mann Type Iteration Method Involving Strictly Hemicontractive Mappings in Banach Spaces
}

\author{
Arif Rafiq ${ }^{1}$ and Shin Min Kang ${ }^{2}$ \\ ${ }^{1}$ Hajvery University, 43-52 Industrial Area, Gulberg-III, Lahore, Pakistan \\ ${ }^{2}$ Department of Mathematics and RINS, Gyeongsang National University, Jinju 660-701, Republic of Korea \\ Correspondence should be addressed to Shin Min Kang, smkang@gnu.ac.kr
}

Received 20 April 2012; Accepted 2 May 2012

Academic Editor: Yonghong Yao

Copyright (C) 2012 A. Rafiq and S. M. Kang. This is an open access article distributed under the Creative Commons Attribution License, which permits unrestricted use, distribution, and reproduction in any medium, provided the original work is properly cited.

We proved that the modified implicit Mann iteration process can be applied to approximate the fixed point of strictly hemicontractive mappings in smooth Banach spaces.

\section{Introduction}

Let $K$ be a nonempty subset of an arbitrary Banach space $X$ and let $X^{*}$ be its dual space. The symbols $D(T)$ and $F(T)$ stand for the domain and the set of fixed points of $T$ (for a singlevalued mapping $T: X \rightarrow X, \quad x \in X$ is called a fixed point of $T$ iff $T x=x$ ). We denote by $J$ the normalized duality mapping from $X$ to $2^{X^{*}}$ defined by

$$
J(x)=\left\{f^{*} \in X^{*}:\left\langle x, f^{*}\right\rangle=\|x\|^{2}=\left\|f^{*}\right\|^{2}\right\}, \quad x \in X,
$$

where $\langle\cdot, \cdot\rangle$ denotes the duality pairing. In a smooth Banach space, $J$ is singlevalued (we denoted by $j$ ).

Remark 1.1. (1) $X$ is called uniformly smooth if $X^{*}$ is uniformly convex.

(2) In a uniformly smooth Banach space, $J$ is uniformly continuous on bounded subsets of $X$.

Let $T: D(T) \subset X \rightarrow X$ be a mapping. 
Definition 1.2. The mapping $T$ is called Lipshitz if there exists a constant $L>0$ such that

$$
\|T x-T y\| \leq L\|x-y\|
$$

for all $x, y \in D(T)$. If $L=1$, then $T$ is called nonexpansive and if $0 \leq L<1$, then $T$ is called contractive.

Definition 1.3 (see $[1,2]$ ). (1) The mapping $T$ is said to be pseudocontractive if

$$
\|x-y\| \leq\|x-y+r((I-T) x-(I-T) y)\|
$$

for all $x, y \in D(T)$ and $r>0$.

(2) The mapping $T$ is said to be strongly pseudocontractive if there exists a constant $t>1$ such that

$$
\|x-y\| \leq\|(1+r)(x-y)-r t(T x-T y)\|
$$

for all $x, y \in D(T)$ and $r>0$.

(3) The mapping $T$ is said to be local strongly pseudocontractive if for each $x \in D(T)$ there exists a constant $t>1$ such that

$$
\|x-y\| \leq\|(1+r)(x-y)-r t(T x-T y)\|
$$

for all $y \in D(T)$ and $r>0$.

(4) The mapping $T$ is said to be strictly hemicontractive if $F(T) \neq \emptyset$ and if there exists a constant $t>1$ such that

$$
\|x-q\| \leq\|(1+r)(x-q)-r t(T x-q)\|
$$

for all $x \in D(T), q \in F(T)$ and $r>0$.

Clearly, each strongly pseudocontractive mapping is local strongly pseudocontractive.

Chidume [1] established that the Mann iteration sequence converges strongly to the unique fixed point of $T$ in case $T$ is a Lipschitz strongly pseudocontractive mapping from a bounded closed convex subset of $L_{p}$ (or $l_{p}$ ) into itself. Schu [3] generalized the result in [1] to both uniformly continuous strongly pseudocontractive mappings and real smooth Banach spaces. Park [4] extended the result in [1] to both strongly pseudocontractive mappings and certain smooth Banach spaces. Rhoades [5] proved that the Mann and Ishikawa iteration methods may exhibit different behaviors for different classes of nonlinear mappings. Afterwards, several generalizations have been made in various directions (see, e.g., $[6-13])$. 
In 2001, $\mathrm{Xu}$ and Ori [14] introduced the following implicit iteration process for a finite family of nonexpansive mappings $\left\{T_{i}: i \in I\right\}$ (here $I=\{1,2, \ldots, N\}$ ) with $\left\{\alpha_{n}\right\}$ a real sequence in $(0,1)$ and an initial point $x_{0} \in K$ :

$$
\begin{aligned}
& x_{1}=\left(1-\alpha_{1}\right) x_{0}+\alpha_{1} T_{1} x_{1}, \\
& x_{2}=\left(1-\alpha_{2}\right) x_{1}+\alpha_{2} T_{2} x_{2}, \\
& \quad \vdots \\
& x_{N}=\left(1-\alpha_{N}\right) x_{N-1}+\alpha_{N} T_{N} x_{N}, \\
& x_{N+1}=\left(1-\alpha_{N+1}\right) x_{N}+\alpha_{N+1} T_{N+1} x_{N+1},
\end{aligned}
$$

which can be written in the following compact form:

$$
x_{n}=\left(1-\alpha_{n}\right) x_{n-1}+\alpha_{n} T_{n} x_{n}, \quad n \geq 1,
$$

where $T_{n}=T_{n(\bmod N)}$ (here the $\bmod N$ function takes values in $\left.I\right)$. $\mathrm{Xu}$ and Ori [14] proved the weak convergence of this process to a common fixed point of the finite family defined in a Hilbert space. They further remarked that it is yet unclear what assumptions on the mappings and/or the parameters $\left\{\alpha_{n}\right\}$ are sufficient to guarantee the strong convergence of the sequence $\left\{x_{n}\right\}$.

In [11], Osilike proved the following results.

Theorem 1.4. Let $X$ be a real Banach space and let $K$ be a nonempty closed convex subset of $X$. Let $\left\{T_{i}: i \in I\right\}$ be $N$ strictly pseudocontractive mappings from $K$ to $K$ with $\mathcal{F}=\bigcap_{i=1}^{N} F\left(T_{i}\right) \neq \emptyset$. Let $\left\{\alpha_{n}\right\}$ be a real sequence satisfying the following conditions:

(i) $0<\alpha_{n}<1$,

(ii) $\sum_{n=1}^{\infty}\left(1-\alpha_{n}\right)=\infty$,

(iii) $\sum_{n=1}^{\infty}\left(1-\alpha_{n}\right)^{2}<\infty$.

From arbitrary $x_{0} \in K$, define the sequence $\left\{x_{n}\right\}$ by the implicit iteration process (1.8). Then $\left\{x_{n}\right\}$ converges strongly to a common fixed point of the mappings $\left\{T_{i}: i \in I\right\}$ if and only if $\lim \inf _{n \rightarrow \infty} d\left(x_{n}, \mathcal{F}\right)=0$.

Remark 1.5. One can easily see that for $\alpha_{n}=1-1 / n^{1 / 2}, \sum_{n=1}^{\infty}\left(1-\alpha_{n}\right)^{2}=\infty$. Hence the results of Osilike [11] are needed to be improved.

Let $K$ be a nonempty closed bounded convex subset of an arbitrary smooth Banach space $X$ and let $T: K \rightarrow K$ be a continuous strictly hemicontractive mapping. We proved that the implicit Mann type iteration method converges strongly to a unique fixed point of $T$.

The results presented in this paper extend and improve the corresponding results particularly in $[1,3,4,7,8,10,11,13,15]$.

\section{Preliminaries}

We need the following results. 
Lemma 2.1 (see [4]). Let X be a smooth Banach space. Suppose that one of the following holds:

(a) $J$ is uniformly continuous on any bounded subsets of $X$,

(b) $\langle x-y, j(x)-j(y)\rangle \leq\|x-y\|^{2}$ for all $x, y$ in $X$,

(c) for any bounded subset $D$ of $X$, there is a function $c:[0, \infty) \rightarrow[0, \infty)$ such that

$$
\operatorname{Re}\langle x-y, j(x)-j(y)\rangle \leq c(\|x-y\|)
$$

for all $x, y \in D$, where $c$ satisfies $\lim _{t \rightarrow 0^{+}}(c(t) / t)=0$.

Then for any $\epsilon>0$ and any bounded subset $K$, there exists $\delta>0$ such that

$$
\|s x+(1-s) y\|^{2} \leq(1-2 s)\|y\|^{2}+2 s \operatorname{Re}\langle x, j(y)\rangle+2 s \epsilon,
$$

for all $x, y \in K$ and $s \in[0, \delta]$.

Remark 2.2. (1) If $\mathrm{X}$ is uniformly smooth, then (a) in Lemma 2.1 holds.

(2) If $X$ is a Hilbert space, then (b) in Lemma 2.1 holds.

Lemma 2.3 (see [8]). Let $T: D(T) \subset X \rightarrow X$ be a mapping with $F(T) \neq \emptyset$. Then $T$ is strictly hemicontractive if and only if there exists a constant $t>1$ such that for all $x \in D(T)$ and $q \in F(T)$, there exists $j(x-q) \in J(x-q)$ satisfying

$$
\operatorname{Re}\langle x-T x, j(x-q)\rangle \geq\left(1-\frac{1}{t}\right)\|x-q\|^{2} .
$$

Lemma 2.4 (see [10]). Let $X$ be an arbitrary normed linear space and let $T: D(T) \subset X \rightarrow X$ be a mapping.

(a) If $T$ is a local strongly pseudocontractive mapping and $F(T) \neq \emptyset$, then $F(T)$ is a singleton and $T$ is strictly hemicontractive.

(b) If $T$ is strictly hemicontractive, then $F(T)$ is a singleton.

Lemma 2.5 (see [10]). Let $\left\{\theta_{n}\right\},\left\{\sigma_{n}\right\}$, and $\left\{\omega_{n}\right\}$ be nonnegative real sequences and let $\epsilon^{\prime}>0$ be a constant satisfying

$$
\sigma_{n+1} \leq\left(1-\theta_{n}\right) \sigma_{n}+\epsilon^{\prime} \theta_{n}+\omega_{n}, \quad n \geq 1,
$$

where $\sum_{n=1}^{\infty} \theta_{n}=\infty, \theta_{n} \leq 1$ for all $n \geq 1$ and $\sum_{n=1}^{\infty} \omega_{n}<\infty$. Then $\lim \sup _{n \rightarrow \infty} \sigma_{n} \leq \epsilon^{\prime}$.

\section{Main Results}

We now prove our main results.

Lemma 3.1. Let $X$ be a smooth Banach space. Suppose that one of the following holds:

(a) $J$ is uniformly continuous on any bounded subsets of $X$, 
(b) $\langle x-y, j(x)-j(y)\rangle \leq\|x-y\|^{2}$ for all $x, y$ in $X$,

(c) for any bounded subset $D$ of $X$, there is a function $c:[0, \infty) \rightarrow[0, \infty)$ such that

$$
\operatorname{Re}\langle x-y, j(x)-j(y)\rangle \leq c(\|x-y\|)
$$

for all $x, y \in D$, where $c$ satisfies $\lim _{t \rightarrow 0^{+}} c((t) / t)=0$.

Then for any $\epsilon>0$ and any bounded subset $K$, there exists $\delta>0$ such that

$$
\begin{aligned}
\|\alpha x+\beta y+\gamma z\|^{2} \leq & (1-2 \alpha)\|x\|^{2}+2 \frac{\alpha \beta}{1-\alpha} \operatorname{Re}\langle y, j(x)\rangle \\
& +2 \frac{\alpha \gamma}{1-\alpha} \operatorname{Re}\langle z, j(x)\rangle+2 \epsilon \alpha
\end{aligned}
$$

for all $x, y, z \in K$ and $\alpha, \beta, \gamma \in[0, \delta] ; \alpha+\beta+\gamma=1$.

Proof. For $\alpha, \beta, \gamma \in[0, \delta] ; \alpha+\beta+\gamma=1$, by using (2.2), consider

$$
\begin{aligned}
\|\alpha x+\beta y+\gamma z\|^{2} & =\left\|\alpha x+(1-\alpha)\left(\frac{\beta}{1-\alpha} y+\frac{\gamma}{1-\alpha} z\right)\right\|^{2} \\
& \leq(1-2 \alpha)\|x\|^{2}+2 \epsilon \alpha+2 \alpha \operatorname{Re}\left\langle\frac{\beta}{1-\alpha} y+\frac{\gamma}{1-\alpha} z, j(x)\right\rangle \\
& =(1-2 \alpha)\|x\|^{2}+2 \epsilon \alpha+2 \frac{\alpha \beta}{1-\alpha} \operatorname{Re}\langle y, j(x)\rangle+2 \frac{\alpha \gamma}{1-\alpha} \operatorname{Re}\langle z, j(x)\rangle .
\end{aligned}
$$

This completes the proof.

Theorem 3.2. Let $X$ be a smooth Banach space satisfying any one of the Axioms (a)-(c) of Lemma 3.1. Let $K$ be a nonempty closed bounded convex subset of $X$ and let $T: K \rightarrow K$ be a continuous strictly hemicontractive mapping. Let $\left\{\alpha_{n}\right\},\left\{\beta_{n}\right\}$ and $\left\{\gamma_{n}\right\}$ be real sequences in $[0,1]$ satisfying conditions

(iv) $\alpha_{n}+\beta_{n}+\gamma_{n}=1$, for all $n \geq 1$,

(v) $\sum_{n=1}^{\infty} \alpha_{n}=\infty$,

(vi) $\sum_{n=1}^{\infty} \beta_{n}<\infty$ and $\sum_{n=1}^{\infty} \gamma_{n}<\infty$.

For a sequence $\left\{v_{n}\right\}$ in $K$, suppose that $\left\{x_{n}\right\}$ is the sequence generated from an arbitrary $x_{0} \in K$ by

$$
x_{n}=\alpha_{n} x_{n-1}+\beta_{n} T x_{n}+\gamma_{n} T v_{n}, \quad n \geq 1,
$$

satisfying $\sum_{n=1}^{\infty}\left\|v_{n}-x_{n}\right\|<\infty$.

Then the sequence $\left\{x_{n}\right\}$ converges strongly to a unique fixed point $q$ of $T$.

Proof. By [2, Corollary 1], $T$ has a unique fixed point $q$ in $K$. It follows from Lemma 2.4 that $F(T)$ is a singleton. That is, $F(T)=\{q\}$ for some $q \in K$. 
Set $M=1+$ diam $K$. It is easy to verify that

$$
M=\sup _{n \geq 1}\left\|x_{n}-q\right\|+\sup _{n \geq 1}\left\|T x_{n}-q\right\|+\sup _{n \geq 1}\left\|T v_{n}-q\right\| .
$$

Also

$$
\begin{aligned}
\left\|v_{n}-q\right\|^{2} & \leq\left\|v_{n}-x_{n}\right\|^{2}+\left\|x_{n}-q\right\|^{2}+2\left\|v_{n}-x_{n}\right\|\left\|x_{n}-q\right\| \\
& \leq\left\|v_{n}-x_{n}\right\|^{2}+\left\|x_{n}-q\right\|^{2}+2 M\left\|v_{n}-x_{n}\right\| .
\end{aligned}
$$

Consider

$$
\begin{aligned}
\left\|x_{n}-q\right\|^{2}= & \left\|\alpha_{n} x_{n-1}+\beta_{n} T x_{n}+\gamma_{n} T v_{n}-q\right\|^{2} \\
= & \left\|\alpha_{n}\left(x_{n-1}-q\right)+\beta_{n}\left(T x_{n}-q\right)+\gamma_{n}\left(T v_{n}-q\right)\right\|^{2} \\
\leq & \alpha_{n}\left\|x_{n-1}-q\right\|^{2} \\
& +\beta_{n}\left\|T x_{n}-q\right\|^{2}+\gamma_{n}\left\|T v_{n}-q\right\|^{2} \\
\leq & \left\|x_{n-1}-q\right\|^{2}+M^{2}\left(\beta_{n}+\gamma_{n}\right),
\end{aligned}
$$

where the first inequality holds by the convexity of $\|\cdot\|^{2}$.

Now we put $k=1 / t$, where $t$ satisfies (2.3). Using (3.4) and Lemma 3.1, we infer that

$$
\begin{aligned}
\left\|x_{n}-q\right\|^{2}= & \left\|\alpha_{n} x_{n-1}+\beta_{n} T x_{n}+\gamma_{n} T v_{n}-q\right\|^{2} \\
= & \left\|\alpha_{n}\left(x_{n-1}-q\right)+\beta_{n}\left(T x_{n}-q\right)+\gamma_{n}\left(T v_{n}-q\right)\right\|^{2} \\
\leq & \left(1-2 \alpha_{n}\right)\left\|x_{n-1}-q\right\|^{2}+2 \frac{\alpha_{n} \beta_{n}}{1-\alpha_{n}} \operatorname{Re}\left\langle T x_{n}-q, j\left(x_{n-1}-q\right)\right\rangle \\
& +2 \frac{\alpha_{n} \gamma_{n}}{1-\alpha_{n}} \operatorname{Re}\left\langle T v_{n}-q, j\left(x_{n-1}-q\right)\right\rangle+2 \epsilon \alpha_{n} \\
= & \left(1-2 \alpha_{n}\right)\left\|x_{n-1}-q\right\|^{2}+2 \frac{\alpha_{n} \beta_{n}}{1-\alpha_{n}} \operatorname{Re}\left\langle T x_{n}-q, j\left(x_{n}-q\right)\right\rangle \\
& +2 \frac{\alpha_{n} \beta_{n}}{1-\alpha_{n}} \operatorname{Re}\left\langle T x_{n}-q, j\left(x_{n-1}-q\right)-j\left(x_{n}-q\right)\right\rangle \\
& +2 \frac{\alpha_{n} \gamma_{n}}{1-\alpha_{n}} \operatorname{Re}\left\langle T v_{n}-q, j\left(v_{n}-q\right)\right\rangle \\
& +2 \frac{\alpha_{n} \gamma_{n}}{1-\alpha_{n}} \operatorname{Re}\left\langle T v_{n}-q, j\left(x_{n-1}-q\right)-j\left(v_{n}-q\right)\right\rangle+2 \epsilon \alpha_{n} \\
\leq & \left(1-2 \alpha_{n}\right)\left\|x_{n-1}-q\right\|^{2}+2 \frac{\alpha_{n} \beta_{n}}{1-\alpha_{n}} k\left\|x_{n}-q\right\|^{2} \\
& +2 \frac{\alpha_{n} \beta_{n}}{1-\alpha_{n}}\left\|T x_{n}-q\right\|\left\|j\left(x_{n-1}-q\right)-j\left(x_{n}-q\right)\right\| \\
& +2 \frac{\alpha_{n} \gamma_{n}}{1-\alpha_{n}} k\left\|v_{n}-q\right\|^{2} \\
& +2 \frac{\alpha_{n} \gamma_{n}}{1-\alpha_{n}}\left\|T v_{n}-q\right\|\left\|j\left(x_{n-1}-q\right)-j\left(v_{n}-q\right)\right\|+2 \epsilon \alpha_{n}
\end{aligned}
$$


Journal of Applied Mathematics

$$
\begin{aligned}
\leq & \left(1-2 \alpha_{n}\right)\left\|x_{n-1}-q\right\|^{2}+2 \frac{\alpha_{n} \beta_{n}}{1-\alpha_{n}} k\left\|x_{n}-q\right\|^{2}+2 M \frac{\alpha_{n} \beta_{n}}{1-\alpha_{n}} \delta_{n} \\
& +2 \frac{\alpha_{n} \gamma_{n}}{1-\alpha_{n}} k\left\|v_{n}-q\right\|^{2}+2 M \frac{\alpha_{n} \gamma_{n}}{1-\alpha_{n}} \eta_{n}+2 \epsilon \alpha_{n} \\
\leq & \left(1-2 \alpha_{n}\right)\left\|x_{n-1}-q\right\|^{2}+2 \frac{\alpha_{n} \beta_{n}}{1-\alpha_{n}} k\left\|x_{n}-q\right\|^{2} \\
& +2 \frac{\alpha_{n} \gamma_{n}}{1-\alpha_{n}} k\left\|v_{n}-q\right\|^{2}+2 M \alpha_{n} \max \left\{\delta_{n}, \eta_{n}\right\}+2 \epsilon \alpha_{n},
\end{aligned}
$$

where

$$
\begin{aligned}
& \delta_{n}=\left\|j\left(x_{n-1}-q\right)-j\left(x_{n}-q\right)\right\|, \\
& \eta_{n}=\left\|j\left(x_{n-1}-q\right)-j\left(v_{n}-q\right)\right\| .
\end{aligned}
$$

Also, we have

$$
\begin{aligned}
\left\|x_{n-1}-x_{n}\right\| & =\left\|x_{n-1}-\alpha_{n} x_{n-1}-\beta_{n} T x_{n}-\gamma_{n} T v_{n}\right\| \\
& =\left\|\beta_{n}\left(x_{n-1}-T x_{n}\right)+\gamma_{n}\left(x_{n-1}-T v_{n}\right)\right\| \\
& \leq \beta_{n}\left\|x_{n-1}-T x_{n}\right\|+\gamma_{n}\left\|x_{n-1}-T v_{n}\right\| \\
& \leq 2 M\left(\beta_{n}+\gamma_{n}\right) \\
& <\infty
\end{aligned}
$$

implies

$$
\left\|x_{n-1}-x_{n}\right\| \longrightarrow 0
$$

as $n \rightarrow \infty$, and consequently

$$
\left\|x_{n-1}-v_{n}\right\| \leq\left\|x_{n-1}-x_{n}\right\|+\left\|x_{n}-v_{n}\right\| \longrightarrow 0
$$

as $n \rightarrow \infty$. Since $J$ is uniformly continuous on any bounded subsets of $X$, we have

$$
\delta_{n}, \eta_{n} \longrightarrow 0 \text { as } n \longrightarrow \infty
$$

For any given $\epsilon>0$ and the bounded subset $K$, there exists a $\delta>0$ satisfying (2.2). Note that (3.13) and (vi) ensure that there exists an $N$ such that

$$
\beta_{n}, \gamma_{n}<\min \left\{\delta, \frac{\epsilon}{8 M^{2} k}\right\}, \quad \delta_{n}, \eta_{n} \leq \frac{\epsilon}{4 M^{\prime}}, \quad n \geq N
$$


Now substituting (3.6) in (3.8) to obtain

$$
\begin{aligned}
\left\|x_{n}-q\right\|^{2} \leq & \left(1-2 \alpha_{n}\right)\left\|x_{n-1}-q\right\|^{2}+2 k \alpha_{n}\left\|x_{n}-q\right\|^{2} \\
& +2 M \alpha_{n} \max \left\{\delta_{n}, \eta_{n}\right\}+2 \epsilon \alpha_{n} \\
& +2 \frac{\alpha_{n} \gamma_{n}}{1-\alpha_{n}} k\left(\left\|v_{n}-x_{n}\right\|^{2}+2 M\left\|v_{n}-x_{n}\right\|\right),
\end{aligned}
$$

by using (3.7), implies

$$
\begin{aligned}
\left\|x_{n}-q\right\|^{2} \leq & \left(1-2(1-k) \alpha_{n}\right)\left\|x_{n-1}-q\right\|^{2}+2 \epsilon \alpha_{n} \\
& +2 M^{2} k \alpha_{n}\left(\beta_{n}+\gamma_{n}\right)+2 M \alpha_{n} \max \left\{\delta_{n}, \eta_{n}\right\} \\
& +2 \frac{\alpha_{n} \gamma_{n}}{1-\alpha_{n}} k\left(\left\|v_{n}-x_{n}\right\|^{2}+2 M\left\|v_{n}-x_{n}\right\|\right) \\
\leq & \left(1-2(1-k) \alpha_{n}\right)\left\|x_{n-1}-q\right\|^{2}+3 \epsilon \alpha_{n} \\
& +2 \frac{\alpha_{n} \gamma_{n}}{1-\alpha_{n}} k\left(\left\|v_{n}-x_{n}\right\|^{2}+2 M\left\|v_{n}-x_{n}\right\|\right)
\end{aligned}
$$

for all $n \geq N$.

Put

$$
\begin{gathered}
\sigma_{n}=\left\|x_{n-1}-q\right\|^{2}, \quad \theta_{n}=2(1-k) \alpha_{n}, \quad \epsilon^{\prime}=\frac{3 \epsilon}{2(1-k)}, \\
\omega_{n}=2 \frac{\alpha_{n} \gamma_{n}}{1-\alpha_{n}} k\left(\left\|v_{n}-x_{n}\right\|^{2}+2 M\left\|v_{n}-x_{n}\right\|\right),
\end{gathered}
$$

and we have from (3.16)

$$
\sigma_{n+1} \leq\left(1-\theta_{n}\right) \sigma_{n}+\epsilon^{\prime} \theta_{n}+\omega_{n}, \quad n \geq 1 .
$$

For $k<1 / 2$, set $\delta=1 / 2(1-k)<1$. Because $\alpha_{n} \leq \delta$, we imply $1-\alpha_{n} \geq 1-\delta$ and $2(1-k) \alpha_{n} \leq$ 1. Now observe that $\sum_{n=1}^{\infty} \theta_{n}=\infty, \theta_{n} \leq 1$ for all $n \geq 1$ and $\sum_{n=1}^{\infty} \omega_{n}<\infty$. It follows from Lemma 2.5 that

$$
\limsup _{n \rightarrow \infty}\left\|x_{n}-q\right\|^{2} \leq \epsilon^{\prime}
$$

Letting $\epsilon^{\prime} \rightarrow 0^{+}$, we obtain that $\limsup _{n \rightarrow \infty}\left\|x_{n}-q\right\|^{2}=0$, which implies that $x_{n} \rightarrow q$ as $n \rightarrow \infty$. This completes the proof.

Corollary 3.3. Let $X$ be a smooth Banach space satisfying any one of the Axioms $(a)-(c)$ of Lemma 3.1. Let $K$ be a nonempty closed bounded convex subset of $X$ and let $T: K \rightarrow K$ be a Lipschitz strictly hemicontractive mapping. Let $\left\{\alpha_{n}\right\},\left\{\beta_{n}\right\}$ and $\left\{\gamma_{n}\right\}$ be real sequences in $[0,1]$ satisfying the conditions (iv)-(vi).

From arbitrary $x_{0} \in K$, define the sequence $\left\{x_{n}\right\}$ by the implicit iteration process (3.4). Then the sequence $\left\{x_{n}\right\}$ converges strongly to a unique fixed point $q$ of $T$. 
Corollary 3.4. Let $X$ be a smooth Banach space satisfying any one of the Axioms $(a)-(c)$ of Lemma 3.1. Let $K$ be a nonempty closed bounded convex subset of $X$ and let $T: K \rightarrow K$ be a continuous strictly hemicontractive mapping. Suppose that $\left\{\alpha_{n}\right\}$ be a real sequence in $[0,1]$ satisfying the conditions ( $v$ ) and $\lim _{n \rightarrow \infty} \alpha_{n}=0$.

From arbitrary $x_{0} \in K$, define the sequence $\left\{x_{n}\right\}$ by the implicit iteration process (1.8). Then the sequence $\left\{x_{n}\right\}$ converges strongly to a unique fixed point $q$ of $T$.

Corollary 3.5. Let $X$ be a smooth Banach space satisfying any one of the Axioms $(a)-(c)$ of Lemma 3.1. Let $K$ be a nonempty closed bounded convex subset of $X$ and let $T: K \rightarrow K$ be a Lipschitz strictly hemicontractive mapping. Suppose that $\left\{\alpha_{n}\right\}$ be a real sequence in $[0,1]$ satisfying the conditions $(v)$ and $\lim _{n \rightarrow \infty} \alpha_{n}=0$.

From arbitrary $x_{0} \in K$, define the sequence $\left\{x_{n}\right\}$ by the implicit iteration process (1.8). Then the sequence $\left\{x_{n}\right\}$ converges strongly to a unique fixed point $q$ of $T$.

Remark 3.6. Similar results can be found for the iteration processes involved error terms; we omit the details.

Remark 3.7. Theorem 3.2 and Corollary 3.3 extend and improve Theorem 1.4 in the following directions.

We do not need the assumption $\lim _{\inf } \rightarrow \infty d\left(x_{n}, \mathcal{F}\right)=0$ as in Theorem 1.4.

\section{Applications for Multistep Implicit Iterations}

Let $K$ be a nonempty closed convex subset of a smooth Banach space $X$ and let $T, T_{1}, T_{2}, \ldots, T_{p}$ : $K \rightarrow K(p \geq 2)$ be a family of $p+1$ mappings.

Algorithm 4.1. For a given $\mathrm{x}_{0} \in \mathrm{K}$, compute the sequence $\left\{\mathrm{x}_{n}\right\}$ by the implicit iteration process of arbitrary fixed order $\mathrm{p} \geq 2$ :

$$
\begin{gathered}
x_{n}=\alpha_{n} x_{n-1}+\beta_{n} T x_{n}+\gamma_{n} T_{1} y_{n}^{1} \\
y_{n}^{i}=\beta_{n}^{i} x_{n-1}+\left(1-\beta_{n}^{i}\right) T_{i+1} y_{n}^{i+1}, \quad i=1,2, \ldots, p-2, \\
y_{n}^{p-1}=\beta_{n}^{p-1} x_{n-1}+\left(1-\beta_{n}^{p-1}\right) T_{p} x_{n}, \quad n \geq 1,
\end{gathered}
$$

which is called the multistep implicit iteration process, where $\left\{\alpha_{n}\right\},\left\{\beta_{n}\right\},\left\{\gamma_{n}\right\}$, and $\left\{\beta_{n}^{i}\right\}, i=$ $1,2, \ldots, p-1$ are real sequences in $[0,1]$ and $\alpha_{n}+\beta_{n}+\gamma_{n}=1$, for all $n \geq 1$.

For $p=3$, we obtain the following three-step implicit iteration process.

Algorithm 4.2. For a given $x_{0} \in K$, compute the sequence $\left\{x_{n}\right\}$ by the iteration process

$$
\begin{gathered}
x_{n}=\alpha_{n} x_{n-1}+\beta_{n} T x_{n}+\gamma_{n} T_{1} y_{n}^{1}, \\
y_{n}^{1}=\beta_{n}^{1} x_{n-1}+\left(1-\beta_{n}^{1}\right) T_{2} y_{n}^{2} \\
y_{n}^{2}=\beta_{n}^{2} x_{n-1}+\left(1-\beta_{n}^{2}\right) T_{3} x_{n}, \quad n \geq 1,
\end{gathered}
$$


where $\left\{\alpha_{n}\right\},\left\{\beta_{n}\right\},\left\{\gamma_{n}\right\},\left\{\beta_{n}^{1}\right\}$ and $\left\{\beta_{n}^{2}\right\}$ are real sequences in $[0,1]$ satisfying some certain conditions.

For $p=2$, we obtain the following two-step implicit iteration process.

Algorithm 4.3. For a given $x_{0} \in K$, compute the sequence $\left\{x_{n}\right\}$ by the iteration process

$$
\begin{gathered}
x_{n}=\alpha_{n} x_{n-1}+\beta_{n} T x_{n}+\gamma_{n} T_{1} y_{n}^{1}, \\
y_{n}^{1}=\beta_{n}^{1} x_{n-1}+\left(1-\beta_{n}^{1}\right) T_{2} x_{n}, \quad n \geq 1,
\end{gathered}
$$

where $\left\{\alpha_{n}\right\},\left\{\beta_{n}\right\},\left\{\gamma_{n}\right\}$ and $\left\{\beta_{n}^{1}\right\}$ are real sequences in $[0,1]$ satisfying some certain conditions. If $T_{1}=T, T_{2}=I$ and $\beta_{n}^{1}=0$ in (4.3), we obtain the following implicit Mann iteration process.

Algorithm 4.4. For any given $x_{0} \in K$, compute the sequence $\left\{x_{n}\right\}$ by the iteration process

$$
x_{n}=\alpha_{n} x_{n-1}+\left(1-\alpha_{n}\right) T x_{n}, \quad n \geq 1,
$$

where $\left\{\alpha_{n}\right\}$ is a real sequence in $[0,1]$ satisfying some certain conditions.

Theorem 4.5. Let $X$ be a smooth Banach space satisfying any one of the Axioms (a)-(c) of Lemma 3.1. Let $K$ be a nonempty closed bounded convex subset of $X$ and let $T, T_{1}, T_{2}, \ldots, T_{p}: K \rightarrow$ $K(p \geq 2)$ be $p+1$ mappings. Let $T, T_{1}$ be continuous strictly hemicontractive mappings. Let $\left\{\alpha_{n}\right\}$, $\left\{\beta_{n}\right\},\left\{\gamma_{n}\right\}$ and $\left\{\beta_{n}^{i}\right\}, i=1,2, \ldots, p-1$ be real sequences in $[0,1]$ satisfying the conditions (iv)-(vi) and $\sum_{n=1}^{\infty}\left(1-\beta_{n}^{1}\right)<\infty$. For arbitrary $x_{0} \in K$, define the sequence $\left\{x_{n}\right\}$ by (4.1). Then $\left\{x_{n}\right\}$ converges strongly to the common fixed point of $\bigcap_{i=1}^{p} F\left(T_{i}\right) \cap F(T) \neq \emptyset$.

Proof. By applying Theorem 3.2 under assumption that $T$ and $T_{1}$ are continuous strictly hemicontractive mappings, we obtain Theorem 4.5 which proves strong convergence of the iteration process defined by (4.1). Consider by taking $T_{1}=T$ and $v_{n}=y_{n}^{1}$,

$$
\begin{aligned}
\left\|v_{n}-x_{n}\right\| & =\left\|y_{n}^{1}-x_{n}\right\| \\
& =\left\|\beta_{n}^{1} x_{n-1}+\left(1-\beta_{n}^{1}\right) T_{2} y_{n}^{2}-x_{n}\right\| \\
& =\left\|\beta_{n}^{1}\left(x_{n-1}-x_{n}\right)+\left(1-\beta_{n}^{1}\right)\left(T_{2} y_{n}^{2}-x_{n}\right)\right\| \\
& \leq \beta_{n}^{1}\left\|x_{n-1}-x_{n}\right\|+\left(1-\beta_{n}^{1}\right)\left\|T_{2} y_{n}^{2}-x_{n}\right\| \\
& \leq \beta_{n}^{1}\left\|x_{n-1}-x_{n}\right\|+M^{\prime}\left(1-\beta_{n}^{1}\right) .
\end{aligned}
$$

From (4.5) and the condition $\sum_{n=1}^{\infty}\left(1-\beta_{n}^{1}\right)<\infty$, we obtain

$$
\sum_{n=1}^{\infty}\left\|v_{n}-x_{n}\right\|<\infty
$$

This completes the proof. 
Corollary 4.6. Let $X$ be a smooth Banach space satisfying any one of the Axioms (a)-(c) of Lemma 3.1. Let $K$ be a nonempty closed bounded convex subset of $X$ and let $T, T_{1}, T_{2}, \ldots, T_{p}: K \rightarrow$ $K(p \geq 2)$ be $p+1$ mappings. Let $T, T_{1}$ be Lipschitz strictly hemicontractive mappings. Let $\left\{\alpha_{n}\right\},\left\{\beta_{n}\right\}$, $\left\{\gamma_{n}\right\}$ and $\left\{\beta_{n}^{i}\right\}, i=1,2, \ldots, p-1$ be real sequences in $[0,1]$ satisfying the conditions (iv)-(vi) and $\sum_{n=1}^{\infty}\left(1-\beta_{n}^{1}\right)<\infty$. For arbitrary $x_{0} \in K$, define the sequence $\left\{x_{n}\right\}$ by (4.1). Then $\left\{x_{n}\right\}$ converges strongly to the common fixed point of $\bigcap_{i=1}^{p} F\left(T_{i}\right) \cap F(T) \neq \emptyset$.

\section{References}

[1] C. E. Chidume, "Iterative approximation of fixed points of Lipschitzian strictly pseudocontractive mappings," Proceedings of the American Mathematical Society, vol. 99, no. 2, pp. 283-288, 1987.

[2] K. Deimling, "Zeros of accretive operators," Manuscripta Mathematica, vol. 13, pp. 365-374, 1974.

[3] J. Schu, "Iterative construction of fixed points of strictly pseudocontractive mappings," Applicable Analysis, vol. 40, no. 2-3, pp. 67-72, 1991.

[4] J. A. Park, "Mann-iteration process for the fixed point of strictly pseudocontractive mapping in some Banach spaces," Journal of the Korean Mathematical Society, vol. 31, no. 3, pp. 333-337, 1994.

[5] B. E. Rhoades, "Comments on two fixed point iteration methods," Journal of Mathematical Analysis and Applications, vol. 56, no. 3, pp. 741-750, 1976.

[6] S. S. Chang, "Some problems and results in the study of nonlinear analysis," Nonlinear Analysis A, vol. 30, pp. 4197-4208, 1997.

[7] S. S. Chang, Y. J. Cho, B. S. Lee, J. S. Jung, and S. M. Kang, "Iterative approximations of fixed points and solutions for strongly accretive and strongly pseudo-contractive mappings in Banach spaces," Journal of Mathematical Analysis and Applications, vol. 224, no. 1, pp. 149-165, 1998.

[8] C. E. Chidume and M. O. Osilike, "Fixed point iterations for strictly hemi-contractive maps in uniformly smooth Banach spaces," Numerical Functional Analysis and Optimization, vol. 15, no. 7-8, pp. 779-790, 1994.

[9] Z. Liu and S. M. Kang, "Stability of Ishikawa iteration methods with errors for strong pseudocontractions and nonlinear equations involving accretive operators in arbitrary real Banach spaces," Mathematical and Computer Modelling, vol. 34, no. 3-4, pp. 319-330, 2001.

[10] Z. Liu, S. M. Kang, and S. H. Shim, "Almost stability of the Mann iteration method with errors for strictly hemi-contractive operators in smooth Banach spaces," Journal of the Korean Mathematical Society, vol. 40, no. 1, pp. 29-40, 2003.

[11] M. O. Osilike, "Implicit iteration process for common fixed points of a finite family of strictly pseudocontractive maps," Journal of Mathematical Analysis and Applications, vol. 294, no. 1, pp. 73-81, 2004.

[12] S. Reich, "Constructive techniques for accretive and monotone operators," in Applied Nonlinear Analysis, pp. 335-345, Academic Press, New York, NY, USA, 1979.

[13] X. Weng, "Fixed point iteration for local strictly pseudo-contractive mapping," Proceedings of the American Mathematical Society, vol. 113, no. 3, pp. 727-731, 1991.

[14] H.-K. Xu and R. G. Ori, "An implicit iteration process for nonexpansive mappings," Numerical Functional Analysis and Optimization, vol. 22, no. 5-6, pp. 767-773, 2001.

[15] W. R. Mann, "Mean value methods in iteration," Proceedings of the American Mathematical Society, vol. 4, pp. 506-510, 1953. 


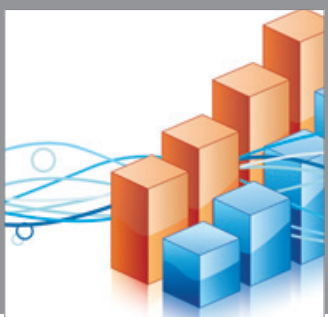

Advances in

Operations Research

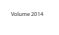

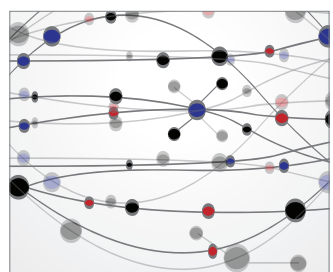

\section{The Scientific} World Journal
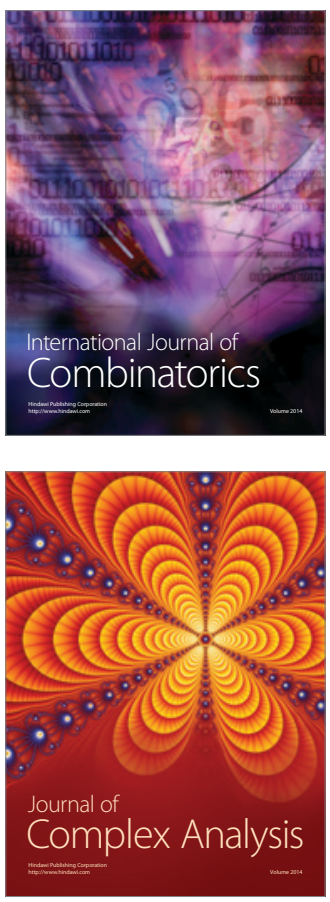

International Journal of

Mathematics and

Mathematical

Sciences
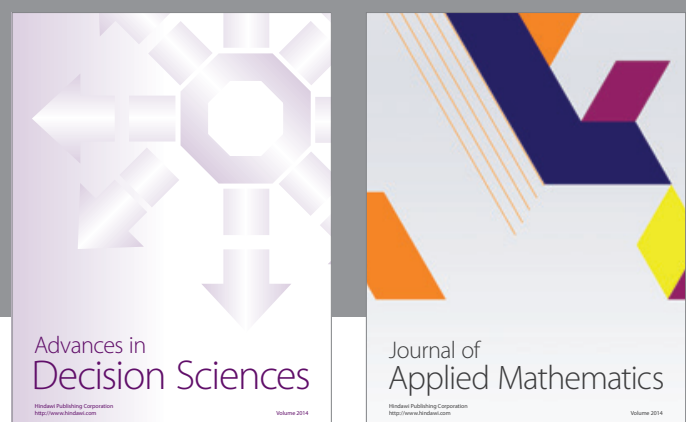

Journal of

Applied Mathematics
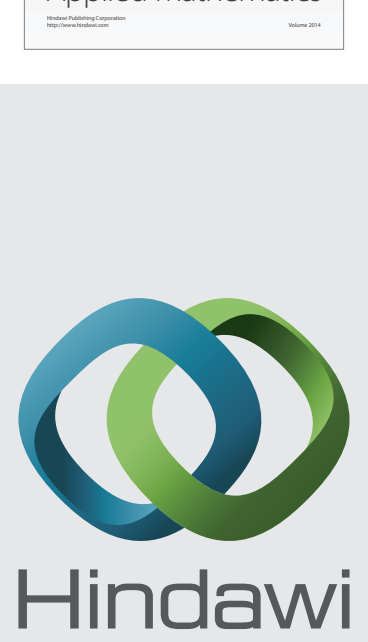

Submit your manuscripts at http://www.hindawi.com
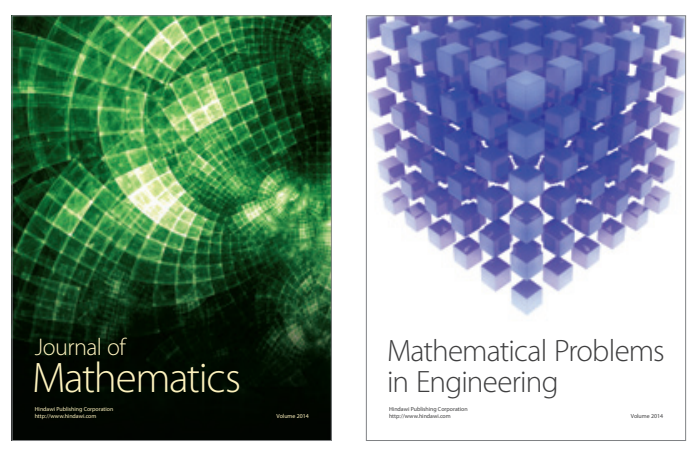

Mathematical Problems in Engineering
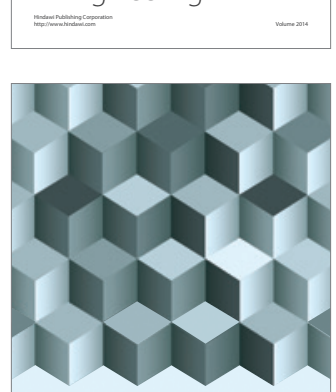

Journal of

Function Spaces
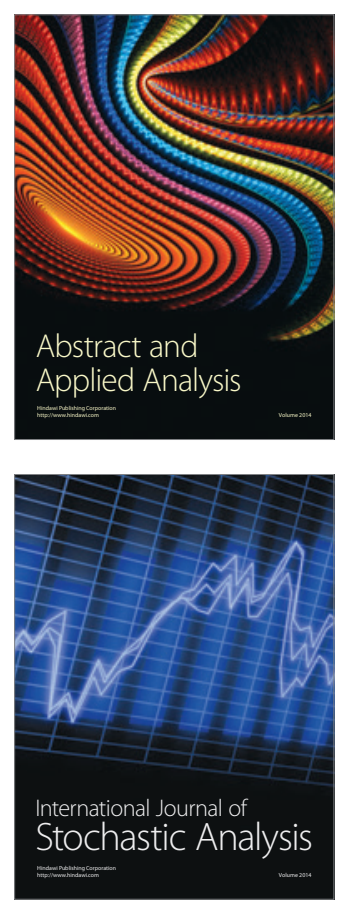

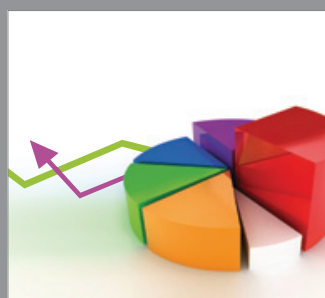

ournal of

Probability and Statistics

Promensencen
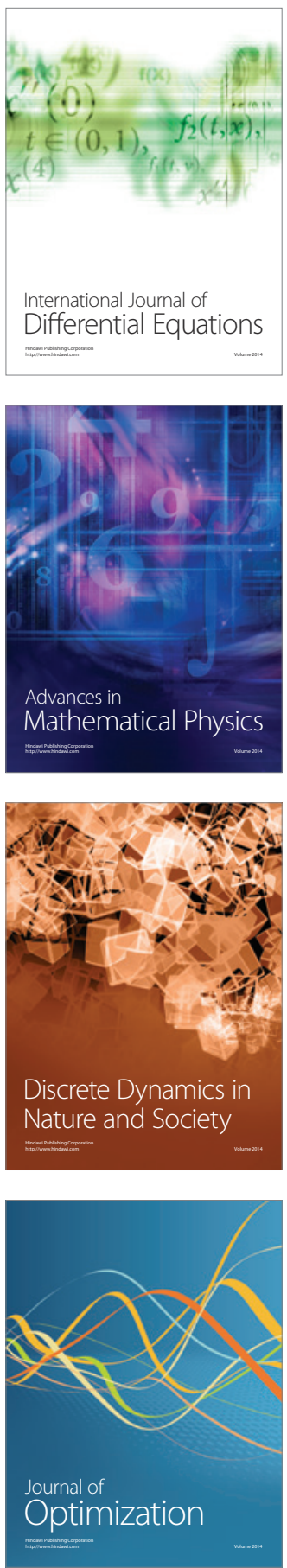